\title{
The Outcome of Management of Distal Third Femoral Shaft Fractures with Retrograde Fin Nailing
}

Dr. Md. Nazmul Huda ${ }^{1 *}$, Dr. Mohammad Kamal Hossain ${ }^{2}$, Dr. Md. Ashik Salauddin ${ }^{3}$, Md. Mizanur Rahman ${ }^{4}$, Dr. Md. Harun-OrRashid $^{5}$, Dr. Shamima Akhter

${ }^{1}$ Assistant Professor, Department of Orthopaedic Surgery, Shaheed Suhrawardy Medical College, Dhaka, Bangladesh

${ }^{2}$ Assistant Professor, Department of Orthopaedic Surgery, Chandpur Medical College, Chandpur, Bangladesh

${ }^{3}$ Junior Consultant, Department of Orthopaedic Surgery, 250 Beded General Hospitals, Gopalgonj, Bangladesh

${ }^{4}$ Junior Consultant, Dept. of Orthopaedic surgery, Dhaka Medical college Hospital, Dhaka, Bangladesh

${ }^{5}$ Assistant Professor, Department of Surgery, Chandpur Medical College, Chandpur, Bangladesh

${ }^{6}$ Consultant, Department of Paediatrics, Pan Pacific Hospital, Dhaka, Bangladesh

*Corresponding author: Dr. Md. Nazmul Huda

Objective: In this study our main goal is to evaluate the outcome of management of distal third femoral shaft fractures with retrograde Fin nailing. Method: This prospective observational study was carried out at National Institute of Traumatology and Orthopedic Rehabilitation (NITOR), Dhaka from June 2007 to December 2008. Results: During the study, after operation $70 \%$ patients stayed in hospital for 2-3 weeks only where only $30 \%$ patients stayed in hospital for 3-4 weeks. All patients seem to be satisfied from the treatment $100 \%$. 50\% patients found to excellent, $40 \%$ to good and only $10 \%$ to fair. $30 \%$ had $1-2 \mathrm{~cm}$ quadriceps atrophy and $20 \%$ had $2-3 \mathrm{~cm}$ quadriceps atrophy. $50 \%$ returned to full activity, $40 \%$ returned to preinjury level with mild limitation, $10 \%$ had moderate symptom with routine activity. Conclusion: Distal femoral shaft fracture management is a challenge to the orthopedic surgeons. Closed retrograde fin nailing in distal femoral shaft fracture shows effective management to the patients.

Keywords: distal third femoral shaft fractures, knee joint, retrograde Fin nailing.

Copyright $(\mathcal{O} 2021$ The Author(s): This is an open-access article distributed under the terms of the Creative Commons Attribution 4.0 International License (CC BY-NC 4.0) which permits unrestricted use, distribution, and reproduction in any medium for non-commercial use provided the original author and source are credited.

\section{INTRODUCTION}

Distal femoral shaft fractures are one of the common fractures encountered in orthopedic surgery. These fractures are very difficult to manage. The incidence of malunion, non-union and infection are relatively high. Non operative treatment is consistently associated with poor results. Because of proximity to knee joint, full knee function may be difficult $[1,2]$.

Various methods of treatment of distal femoral shaft fracture include traction followed by cast bracing, external fixation, plating and different forms of intramedullary nails. The treatment of distal femoral factures has undergone a substantial evolution in the last two decades. But traditional Kirschner nail cannot prevent rotation or angulation even in stable fractures in distal third of femur. Intramedullary interlocking nails recently received increased attention for the treatment of distal femoral shaft fractures [3, 4]. These, devices obtain more "biological" fixation because they are load sharing rather than load bearing implant and successfully controlling the axial and rotational deforming forces, especially in distal third and comminuted fractures. The technique started in early 80 's and quickly popularized all over the world due to its effectiveness in controlling rotational and axial malalignment $[5,6]$.

In this study our main goal is to evaluate the outcome of management of distal third femoral shaft fractures with retrograde Fin nailing.

\section{OBJECTIVE}

- To assess the outcome of management of distal third femoral shaft fractures with retrograde Fin nailing.

\section{Methodology}

Type of study

- This prospective observational study

\section{Place and period study}

- The study was carried out at-the National Institute of Traumatology and Orthopedic Rehabilitation 
(NITOR), Dhaka from June 2007 to December 2008 .

\section{Study population}

- 10 patients with distal third femoral shaft fractures were selected and treated with fin nailing. 8 patients were male and 2 patients were female. The mean age was 38.5 years (range 20-60 year). Six fractures were Winquist type I and four fractures were Winquist type II. Most of the fractures were high energy injuries caused by road traffic accidents.

\section{Sampling method}

- Purposive sampling method was followed as per inclusion and exclusion criteria.

\section{Inclusion criteria}

- Age: Adult patients i.e. fracture with distal epiphyseal fusion.

- Fracture: Distal third femoral shaft fractures only.

- Injury: Closed fractures only.

- Injury time: Fresh and less than three weeks old fractures were taken.

- Fracture type: Stable fractures i.e. Winquist type I and type II fractures.

\section{Data collection procedure}

A pretested and predesigned proforma containing history and examination findings of the patient, operative procedure and follow up was used to collect the data.

\section{Data AnALYSIS}

Data were collected, compiled and tabulated according to key variables. All statistical analysis of different variables were carried out according to standard statistical methods and calculations done by using scientific calculator.

\section{RESULTS}

In table-1 shows age distribution of the patients where most of the patients belong to 30-39 years age group. The following table is given below in detail:

Table-1: Age distribution of the patients

\begin{tabular}{|l|l|l|}
\hline Age distribution of the patients & n & \% \\
\hline $20-29$ & 2 & 20 \\
\hline $30-39$ & 4 & 40 \\
\hline $40-49$ & 3 & 30 \\
\hline $50-60$ & 1 & 10 \\
\hline
\end{tabular}

In figure-1 shows gender distribution of the patients where $80 \%$ were male. The following figure is given below in detail:

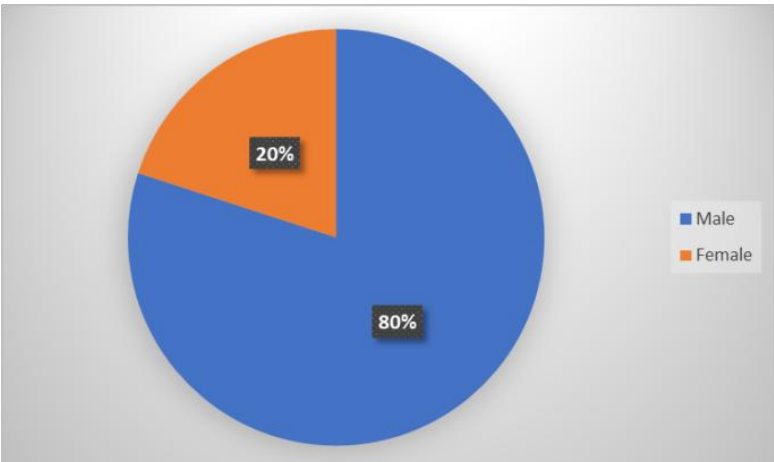

Fig-1: Gender distribution of the patients

In figure-2 shows duration of hospital stay after operation where $70 \%$ patients stayed in hospital for 2-3 weeks only where only $30 \%$ patients stayed in hospital for 3-4 weeks. The following figure is given below in detail:

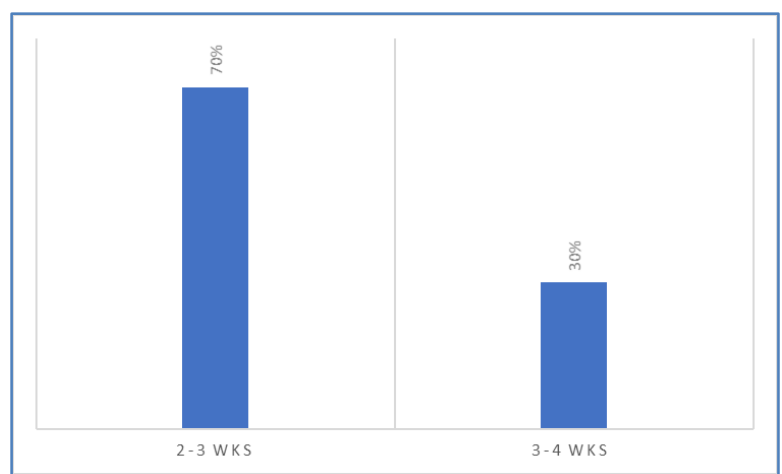

Fig-2: Duration of hospital stay after operation

In table-2 shows outcome during follow-up where all patients seem to be satisfied from the treatment $100 \%$. 50\% patients found to excellent, $40 \%$ to good and only $10 \%$ to fair. The following table is given below in detail:

Table-2: Outcome during follow-up

\begin{tabular}{|l|l|l|}
\hline Result & n & \% \\
\hline Satisfactory: & & \\
Excellent & 5 & $50 \%$ \\
Good & 4 & $40 \%$ \\
Fair & 1 & $10 \%$ \\
\hline Total & 10 & $100 \%$ \\
\hline Unsatisfactory & 0 & 0 \\
\hline
\end{tabular}

In table-3 shows quadriceps atrophy to follow up where $30 \%$ had $1-2 \mathrm{~cm}$ quadriceps atrophy and $20 \%$ had $2-3 \mathrm{~cm}$ quadriceps atrophy. The following table is given below in detail:

Table-3: Quadriceps atrophy to follow up

\begin{tabular}{|l|l|l|}
\hline Quadriceps atrophy & n & \% \\
\hline $1-2 \mathrm{~cm}$ & 3 & $30 \%$ \\
\hline $2-3 \mathrm{~cm}$ & 2 & $20 \%$ \\
\hline Normal & 5 & $50 \%$ \\
\hline
\end{tabular}


Nazmul Huda et al; Sch J App Med Sci, Mar, 2021; 9(3): 401-403

In table-4 shows distribution of the patients according to knee motion where $50 \%$ had 130 degrees knee motion, $30 \%$ had rang of knee motion of $>110$ degrees. The following table is given below in detail:

Table-4: Distribution of the patients according to knee motion

\begin{tabular}{|l|l|l|}
\hline Knee motion & n & \% \\
\hline$>130$ & 5 & $50 \%$ \\
\hline$>110$ & 3 & $30 \%$ \\
\hline$>90$ & 2 & $20 \%$ \\
\hline
\end{tabular}

Table-5 shows functional assessment of the patients $50 \%$ returned to full activity, $40 \%$ returned to preinjury with mild limitation, $10 \%$ had moderate symptom with routine activity. The following table is given below in detail:

Table-5: Functional assessment of the patients

\begin{tabular}{|l|c|l|}
\hline Functional assessment & $\mathrm{n}$ & $\%$ \\
\hline Returned to full activity & 5 & $50 \%$ \\
\hline $\begin{array}{l}\text { Returned to preinjury level with mild } \\
\text { limitation }\end{array}$ & 4 & $40 \%$ \\
\hline $\begin{array}{l}\text { Perform routine activity with moderate } \\
\text { symptom }\end{array}$ & 1 & $10 \%$ \\
\hline
\end{tabular}

\section{DISCUSSION}

In one study found that, average flexion in this study was 100 degree with more than $50 \%$ patients having knee range of motion more than 110 degree. Five $(50 \%)$ patients had knee motion > 130 degrees, three $(30 \%)$ patients had $>110$ degrees \& two $(20 \%)$ patients had $>90$ degrees of motion. In the study of Osti um et al. average range of knee motion was 120 degrees. In the study of Faruquee average range of knee motion was 122.5 degrees.7 There was two cases superficial infection which subsided after debridement and antibiotics. Where as in our study, 50\% had 130 degrees knee motion, $30 \%$ had range of knee motion of $>110$ degrees.

In our study we noted that, $50 \%$ returned to full activity, $40 \%$ returned to preinjury with mild limitation, $10 \%$ had moderate symptom with routine activity. Regarding range of knee motion, five (50\%) patients had knee motion $>130$ degrees, three $(30 \%)$ patients had > 110 degrees \& two $(20 \%)$ patients had > 90 degrees of motion. In the study of Ostrum et al. average range of knee motion was 120 degrees. In the study of Faruquee average range of knee motion was 122.5 degrees. $8 \mathrm{We}$ also found $30 \%$ had $1-2 \mathrm{~cm}$ quadriceps atrophy and $20 \%$ had $2-3 \mathrm{~cm}$ quadriceps atrophy. Which was supported by other studies $[9,10]$.

Also, in our study younger patients attained better results than the elderly patients. Presumably this is because the younger group adhere to strict and vigorous physiotherapy postoperatively than elderly group.

\section{CONCLUSION}

Distal femoral shaft fracture management is a challenge to the orthopedic surgeons. Closed retrograde fin nailing in distal femoral shaft fracture shows effective management to the patients.

\section{REFERENCES}

1. Wilson JN. Watson Jone's: Fractures and joint injuries. 6thed, 10031982.

2. Charnley John. The closed treatment of common fractures. 3rded, 197-204.

3. Hugh Owen Thomas. Quoted by Rockwood CA, Green DP. Fractures in adult, 4thed, 2. 1972-1993, 1996.

4. Fritz Steinman. Quoted by Rockwood CA, Green DP. Fractures in adult, 4thed, 2. 1972-93, 1996.

5. Kenneth J, Koval MD. Supracondtlar and Intercondylar Fractures of the Distal Femur. In Alan M. Levine MD. editor. Orthopaedic Knowledge Update Trauma. American Academy of Orthopaedic Surgeons. 1998; 137-43.

6. Leggon RE. Feldmann DD. 2001: Retrograde femoral nailing: a focus on the knee. Am. J Knee Surg; spring. 2001; 14(2): 109-18. S.

7. Terry Canale, MD; Kay Daugherty; Linda Jones 2003: Compbell's Operative Orthopedics; Tenth ed, Philadelphia, USA. 2003; 3 2810-11.

8. Winquist RA. Hansen ST. 1978 Segmental fractures of the femur treated by closed intramedullary nailing. J. Bone Joint Surg (Am). 1978; 60: 934-9.

9. Russel TA. Biomechanical concepts of femoral intramedullary nailing. Int J Orthop Trauma. 1991; $1: 35$.

10. Netter MD. Atlas of I lnnrr Anatomy, second Edition. East Hanover, Newjercey Heechstetter printing Company Inc. 1998; 475-476. 